\title{
Asbestos pleural effusion: a clinical entity
}

\author{
GUNNAR MÅRTENSSON, STIG HAGBERG, KJELL PETTERSSON, \\ GUNNAR THIRINGER
}

From the Departments of Pulmonary Medicine, Occupational Medicine, and Statistics, University of Göteborg, Sweden

ABSTRACT In a case-control study asbestos exposure in 64 consecutive men with idiopathic pleurain effusion and 129 randomly sampled age matched male controls was compared. Furthermore, seven $n_{5}^{\circ}$ women and 64 men with idiopathic pleural effusion were studied, including a three yearaे re-examination, in an attempt to identify characteristics that might distinguish asbestos exposedo from non-exposed patients. Asbestos exposure was significantly $(p<0.01)$ more frequent in menwith idiopathic effusions than in controls. The idiopathic effusions seen in asbestos exposed patients were compatible with the diagnosis "asbestos pleural effusion." Two features were characteristic of patients with asbestos pleural effusion: a chest radiograph at the initial examination showing 3 converging pleural linear structures or rounded atelectasis or a history of recurrent pleural effusion $\stackrel{\Phi}{\Phi}$ or both.

\section{Introduction}

In 1964 Eisenstadt ${ }^{1}$ described an asbestos insulator with recurrent idiopathic pleural effusion and postulated that the effusions were a response to inhaled asbestos dust. The condition was named "asbestos pleurisy." Subsequent case reports ${ }^{2-10}$ have supported the initial observation. Epler et al ${ }^{11}$ recently reported a greater prevalence of idiopathic effusions among asbestos exposed workers than in workers not exposed to asbestos. They also found a dose-response relationship between asbestos exposure and the occurrence of pleural effusions. The diagnosis of asbestos pleural effusion is at present based on a history of asbestos exposure and exclusion of other probable causes of the effusion. ${ }^{1213}$ Owing to the lack of pathological characteristics and the paucity of evidence, doubts have been raised concerning the existence of "asbestos pleural effusion." 14

The aim of this study was to look for additional evidence of asbestos pleural effusion as a clinical entity. Asbestos exposure in men with idiopathic effusions and in controls was therefore compared in a case-control study. Furthermore, a group of patients with idiopathic effusions was examined in an attempt

Address for reprint requests: Dr Gunnar Mårtensson, Renströmska Hospital, PO Box 17301, S-402 64 Göteborg, Sweden.

Accepted 4 March 1987 to identify characteristics which might distinguish asbestos exposed from non-exposed patients.

\section{Methods}

PATIENTS

From April 1976 to August 197999 women and $235^{3}$ men with pleural effusions lasting at least three week were referred to the Department of Pulmonary Medicine because of inconclusive findings in ab previous examination. A definite cause was found in 92 women and 171 men.

This study concerns the seven women and 64 men?. with idiopathic effusions. The criteria for the diagnosis "idiopathic effusion" were: an initiaB examination including chest radiographs and bloodo sputum, pleural fluid, and pleural tissue analyses as well as a three year re-examination without signs of any probable cause. These results are presented in

Three years after the initial examination 66 of tho 71 patients with idiopathic effusions were still alive స్ల These 66 patients were summoned to re-examination and 61 took part in this examination.

For comparison of occupational histories of asbestos exposure, a control group of 129 age matched men was randomly selected with the assistance of the Göteborg County population register. There were 26 dropouts among the controls $\overrightarrow{\mathbb{D}}$ one died before interview, two were too senile tक्षे cooperate, and 23 refused to participate. Adequatê 

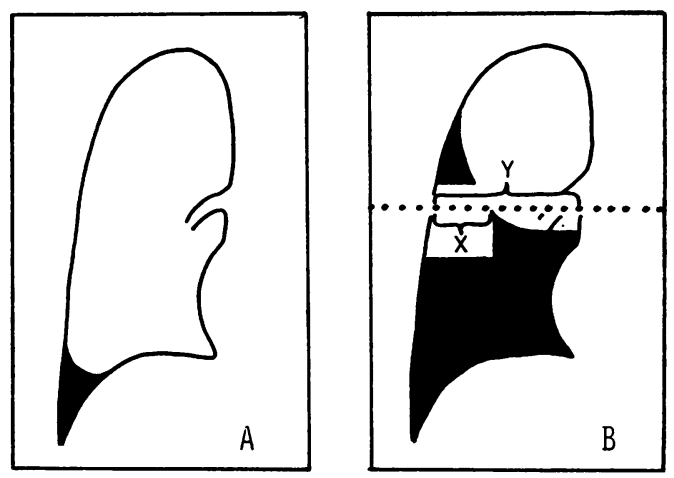

Fig 1 Classification of size of effusion. A-The effusion was classified as small if the entire diaphragm was not covered. B-The effusion was classified as medium if it covered up to one third of the distance between the lateral chest wall and the mediastinum at the level of the hilar region $\left(X / Y<\frac{1}{3}\right)$. An even larger effusion was classified as large $\left(X / Y>\frac{1}{3}\right)$.

occupational histories were thus obtained from 103 $(80 \%)$ of the 129 controls.

\section{ASBESTOS EXPOSURE}

All patients and controls were interviewed and questioned about all occupations they had had during their entire working life. The interviews were standardised by presenting all occupations in chronological order with special reference to occupations associated with asbestos exposure on the basis of a review by Sarrazin. ${ }^{16}$

All patients and one third of the controls were interviewed by a chest physician. One third of the patients and the remaining two thirds of the controls were interviewed by an occupational hygienist. All occupational histories were typewritten.

The occupational histories were evaluated by an occupational hygienist one year after the last interview. All occupational histories from both patients and controls were then mixed with those from 171 other patients, after which all histories were blindly evaluated without knowledge of whether they concerned patients or controls. Asbestos exposure was evaluated in terms of its duration in years and the latency time from the initial exposure. A scanty exposure to asbestos (for less than two days) was regarded as no exposure.

\section{INITIAL EXAMINATION}

The following items obtained at the initial examination were evaluated. Blood analyses included erythrocyte sedimentation rate and IgG concentration. Pleural fluid analyses included fluid colour,
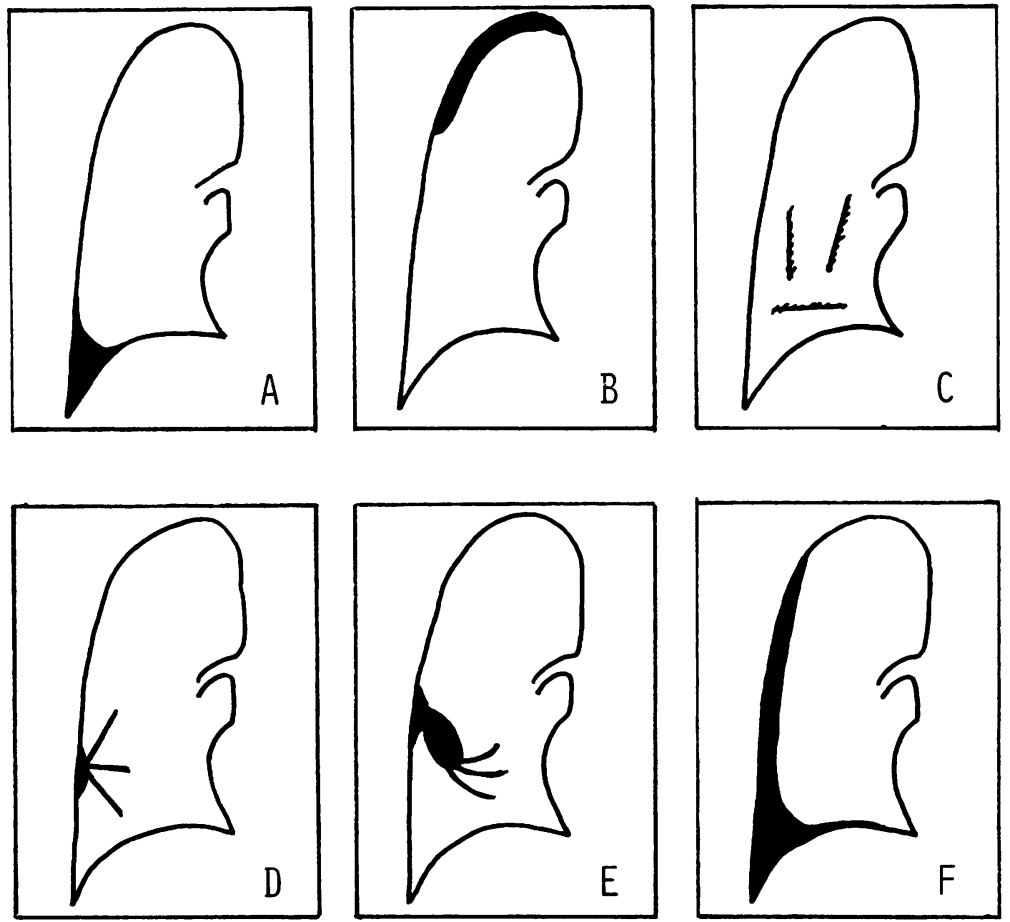

Fig 2 Classification of pleural radiographic lesions. Minor lesions. $A-B l u n t i n g$ of the costophrenic sulci. $B$-Local pleural thickening other than pleural plaques. $C$-Pleural linear structures. Major lesions: $D$-Converging pleural linear structures, also named "crow's feet."7 17 E-Rounded atelectasis. ${ }^{1819}$ F-Diffuse pleural thickening. 
protein content, and eosinophils as shown by a differential leucocyte count. The size of the effusion was classified by a posteroanterior radiograph as small, medium or large (in accordance with fig 1A-B).

Pleural radiographic lesions other than the effusion were classified on posteroanterior and lateral projections as minor (fig $2 \mathrm{~A}-\mathrm{C}$ ) or major lesions (fig 2D-F).

The chest radiographs were evaluated jointly by a radiologist and a chest physician.

\section{THREE YEAR RE-EXAMINATION}

The following items obtained at the three year re-examination were evaluated. Blood analyses included erythrocyte sedimentation rate, $\operatorname{IgG}, \operatorname{IgA}, \mathrm{T}$ lymphocytes (as percentages of all lymphocytes), lymphocyte response to phytohaemagglutinin (PHA), and concanavalin A (Con A). The PHA and Con A results were expressed as the ratio between the obtained value and the predicted value.

Lung function was measured in terms of total lung capacity (TLC) and residual volume (RV) with a constant volume body plethysmograph. Vital capacity (VC), forced expiratory volume in 1 second $\left(\mathrm{FEV}_{1}\right)$ and forced expiratory volume as percentage of vital capacity (FEV\%) were measured with a Bernstein spirometer. Lung elastic recoil, expressed as the maximum transpulmonary pressure (MTP), was measured with a constant volume body plethysmograph and an oesophageal balloon. All results are expressed as percentages of predicted values. ${ }^{2021}$ The predicted MTP values are based on unpublished observations.

Pleural radiographic lesions were classified in the same manner as at the initial examination, but only the additional lesions seen at the follow up examination were considered.

Episodes of recurrent idiopathic effusion before the present effusion or during the follow up period were registered.

\section{Results}

Seven women and 64 men with idiopathic pleural effusions were examined in this study. The patients' ages ranged from 16 to 85 years, with a mean of 50 and a median of 52 years.

Occupational exposure to asbestos was discovered in only two of the seven female patients and no evaluation or analysis was undertaken.

Asbestos exposure was found (table 1) in $\mathbf{4 2}$ of the $64(66 \%)$ male patients but only 45 of $103(44 \%)$ age matched male controls $(p<0.01)$. Identical results were reported by the two interviewers for the 20 male patients interviewed by both interviewers. Among the controls, exposure was reported in 33 out of $70(44 \%)$
Table 1 Exposure to asbestos in 64 men with idiopathic pleural effusion and 129 age matched male controls

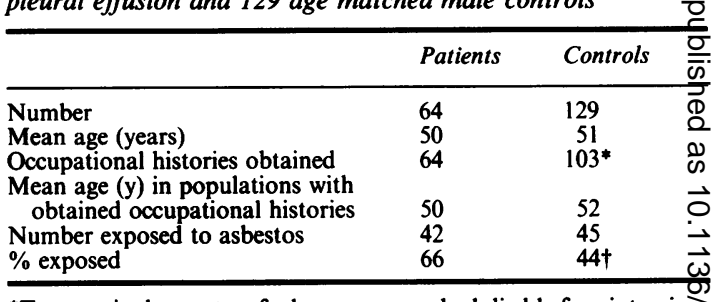

*Twenty six dropouts, of whom one man had died before intervie two were too senile to cooperate, and 23 refused to participate. tp $<0.01$ according to the $\chi^{2}$ test.

interviewed by the occupational hygienist and in $1 \frac{\hat{\sigma}}{2}$ out of $33(39 \%)$ interviewed by the chest physician? The mean duration of exposure was 17 years for patients and 16 years for controls. The mean latenc\&s time from initial exposure to pleural effusion in the patients was 26 years, and to examination in th8 controls 32 years.

The results from the initial examination of the patients with regard to occurrence of asbestoos exposure are presented in table 2. Major lesions on

Table 2 Results of the initial examination of patients with idiopathic pleural effusion, presented in relation to asbestoso exposure (statistical comparisons made between the non-exposed and all exposed patients; number of observations in parentheses)

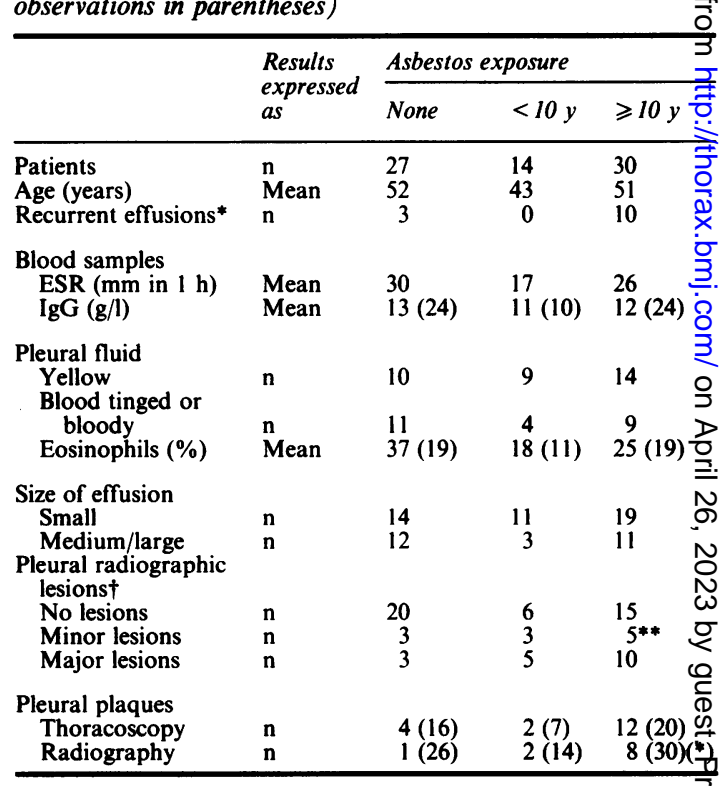

*History of pleural effusion before the current effusion.

†Pleural radiographic lesions excluding effusion and pleural plaqu雨

$\left({ }^{*}\right) \mathrm{p}<0.1$ according to the $\chi^{2}$ test.

$* * \mathrm{p}<0.05$ according to the $\chi^{2}$ test.

ESR-erythrocyte sedimentation rate. 
Table 3 Results of the three year re-examination of patients with idiopathic pleural effusion, presented in relation to asbestos exposure (statistical comparisons made between the non-exposed and all exposed patients; number of observations in parentheses)

\begin{tabular}{|c|c|c|c|c|}
\hline & \multirow{2}{*}{$\begin{array}{l}\text { Results } \\
\text { expressed } \\
\text { as }\end{array}$} & \multicolumn{3}{|c|}{ Asbestos exposure } \\
\hline & & None & $<10 y$ & $\geqslant 10 y$ \\
\hline $\begin{array}{l}\text { Patients } \\
\text { Recurrent effusions* }\end{array}$ & $\begin{array}{l}\mathrm{n} \\
\mathrm{n}\end{array}$ & $\begin{array}{r}22 \\
3\end{array}$ & $\begin{array}{r}12 \\
0\end{array}$ & $\begin{array}{l}27 \\
11\end{array}$ \\
\hline $\begin{array}{l}\text { Blood samples } \\
\text { ESR (mm in } 1 \mathrm{~h}) \\
\text { IgG }(\mathrm{g} / \mathrm{l}) \\
\text { IgA (g/l) } \\
\text { T lymphocytes (\%) } \\
\text { PHA (ratio) } \\
\text { Con A (ratio) }\end{array}$ & $\begin{array}{l}\text { Mean } \\
\text { Mean } \\
\text { Mean } \\
\text { Mean } \\
\text { Mean } \\
\text { Mean }\end{array}$ & $\begin{array}{c}13(19) \\
13(17) \\
3.4(17) \\
67(16) \\
0.9(15) \\
0.9(15)\end{array}$ & $\begin{array}{l}14(11) \\
11(12) \\
3.0(12) \\
68(11) \\
1 \cdot 1(12) \\
0 \cdot 8(12)\end{array}$ & $\begin{array}{c}13(26) \\
12(23) \\
2.9(23) \\
63(20) \\
0.9(19) \\
1.0(19)\end{array}$ \\
\hline $\begin{array}{l}\text { Lung function† } \\
\text { TLC } \\
\text { RV } \\
\text { VC } \\
\text { FEV } \\
\text { MTP }_{(\mathbf{k P a})}\end{array}$ & $\begin{array}{l}\text { Mean } \\
\text { Mean } \\
\text { Mean } \\
\text { Mean } \\
\text { Mean }\end{array}$ & $\begin{array}{r}87(16) \\
86(16) \\
80(18) \\
82(18) \\
110(16)\end{array}$ & $\begin{array}{l}89(10) \\
101(10) \\
78(11) \\
81(11) \\
131(9)\end{array}$ & $\begin{array}{r}89(24) \\
93(24) \\
80(24) \\
85(24) \\
123(22)\end{array}$ \\
\hline $\begin{array}{l}\text { Additional radiograph } \\
\text { None } \\
\text { Minor lesions } \\
\text { Major lesions }\end{array}$ & $\begin{array}{l}\text { c lesions }+ \\
n \\
n \\
n\end{array}$ & $\begin{array}{r}3 \\
11 \\
8\end{array}$ & $\begin{array}{l}5 \\
2 \\
5\end{array}$ & $\begin{array}{l}10 \\
14\left(^{*}\right) \\
2\end{array}$ \\
\hline
\end{tabular}

*History of pleural effusion before the current effusion or relapse during the follow up period.

†Lung function measurements expressed as percentage of predicted value.

†Additional radiographic pleural lesions since the initial examination.

$\left.{ }^{*}\right) p<0.1$ according to the $\chi^{2}$ test.

ESR - erythrocyte sedimentation rate; PHA - phytohaemagglutinin Con A-concanavalin A; TLC - total lung capacity; RV-residual volume; VC - vital capacity; MTP-maximum transpulmonary pressure.

the chest radiograph were significantly $(p<0.05)$ more common in asbestos exposed patients. Converging pleural linear structures (fig 2D) and rounded atelectasis (fig $2 \mathrm{E}$ ) were seen in nine asbestos exposed and two non-exposed patients. Diffuse pleural thickening was seen in two asbestos exposed and one non-exposed patient. Converging pleural linear structures or rounded atelectasis combined with diffuse pleural thickening were seen in four asbestos exposed patients.

A history of recurrent idiopathic pleural effusion was more frequent in asbestos exposed than in non-exposed men. This difference was significant $(p<0.05)$ if the comparison was made between those with a duration of asbestos exposure of at least 10 years and those with shorter or no exposure.

Pleural plaques were associated with asbestos exposure $(\mathrm{p}<0 \cdot 1)$.

Results obtained at the three year re-examination of the patients are presented in relation to asbestos exposure in table 3 . A difference between exposed and non-exposed patients was found for a history of recurrent effusion before the initial examination or during the three year follow up period. This difference was significant $(p<0.01)$ if the comparison was made between those with a duration of exposure of at least 10 years and those with shorter or no exposure. Three patients, all exposed for more than 10 years, had episodes of recurrent effusion during the three year follow up period. Two of these three patients had also had recurrent effusions before the initial examination.

Differences were also seen between exposed and non-exposed patients in the development of additional radiographic lesions seen at the three year re-examination $(\mathrm{p}<0 \cdot 1)$.

\section{Discussion}

Idiopathic pleural effusions have often been considered to be effusions of tuberculous, ${ }^{22} 23$ or viral $^{24}$ aetiology. The expression "idiopathic pleural effusion presumably tuberculous" 25 was until recently commonly used.

In a prospective study of 334 consecutive patients with long term pleural effusions, ${ }^{152627}$ part of which is reported in this paper, $71(21 \%)$ patients were shown to have "idiopathic" effusions. Of these 71 patients with idiopathic effusions, $64(90 \%)$ were men and asbestos exposure was significantly $(p<0.01)$ more frequent among these men than among age matched male controls. The percentage of asbestos exposed male patients exceeded the percentage of exposed controls by $20 \%$. Twenty per cent of the male patients corresponds to 14 of the 64 patients. These results indicate that asbestos exposure is today a common, but not the only, cause of "idiopathic" pleural effusion, at least in industrial countries.

Several possible errors must, however, be considered. One possibility is that asbestos associated malignant effusions were included by mistake. The extensive diagnostic efforts made, ${ }^{15}$ and the three year follow up period without signs of malignancy, argue against a malignant aetiology.

The occupational histories were obtained and evaluated in a similar manner for patients and controls. The proportion identified as having been exposed to asbestos was almost identical for the corresponding groups of patients and controls interviewed by the chest physician and the occupational hygienist. The identification of the interviewer was prevented by typewriting all interviews in a similar manner. The identification of whether the subject at evaluation was a patient or a control was prevented by mixing the occupational histories obtained with occupational histories from others and then performing a blind evaluation.

The dropouts among the controls were evenly distributed between young and old people; they were 
so few (26 out of 129) that they could not have affected the results.

The most reasonable explanation of the many asbestos exposed patients with idiopathic pleural effusions seen in this study is that these effusions represent "asbestos pleural effusions" as described by Einsenstadt ${ }^{1}$ and others. ${ }^{2-11}$

The initial examination of patients with idiopathic effusions showed that pleural radiographic lesions excluding effusions and pleural plaques were the feature that most strongly distinguished asbestos exposed from non-exposed patients. Converging pleural linear structures and rounded atelectasis, alone or in combination with diffuse pleural thickening, were almost exclusively seen in asbestos exposed patients. These lesions have also been described in association with asbestos exposure by others. $^{79192829}$ During the follow up period, however, linear structures converging towards the pleura and rounded atelectasis developed, as single major lesions or combined with diffuse pleural thickening, not only in five exposed patients but also in six non-exposed patients. This result, which somewhat contradicts our findings at the initial examination, could be due to a remote and now forgotten asbestos exposure. This possibility is supported by the fact that three of the six "non-exposed" patients showed pleural plaques on thoracoscopy. These results are of interest as converging pleural linear structures and rounded atelectasis seldom occur in association with pleural effusion of any other known cause. ${ }^{27}$

Another factor that strongly distinguished asbestos exposed from non-exposed patients was a history of recurrent pleural effusion. Several case reports have shown that asbestos pleural effusions are often recurrent. $^{2610}$ In this study we also noted that the increased occurrence of recurrent effusions was entirely related to patients exposed for at least 10 years. This in turn suggests a dose-response relation between asbestos exposure and the development of asbestos pleural effusion. Most of the effusions seen in asbestos exposed patients were small, as reported by other investigators. ${ }^{1011}$

Immunological reactions were studied at the three year re-examination as disturbances have been seen in association with asbestosis. A fourfold increase of the incidence of antinuclear and rheumatoid factors, ${ }^{30}$ raised immunoglobulin concentrations, ${ }^{31}{ }^{32}$ and a depletion of T lymphocytes ${ }^{3133}$ is reported in persons with parenchymal asbestosis. The fact that no immunological differences were seen between the asbestos exposed and non-exposed patients in this study could be due to differences in immunological response between parenchymal and pleural disease.

In summary, this study has shown that idiopathic pleural effusions were mainly seen in asbestos exposed $\overrightarrow{\vec{S}}$ men. Asbestos exposure was significantly more $\overrightarrow{0}$ frequent among these men than among age matched $\frac{C}{0}$ controls. The idiopathic effusions seen in asbestos $\overline{\bar{\sigma}}$ exposed patients were compatible with the clinical $\overparen{\nabla}$ entity "asbestos pleural effusion." Two features $\varrho$ distinguished asbestos pleural effusions from के idiopathic effusions in non-exposed patients: certain $\vec{\circ}$ radiographic lesions (converging pleural linear $\overrightarrow{\vec{H}}$ structures or rounded atelectasis) seen at the initial $\vec{\sigma}^{\circ}$ examination or a history of recurrent effusion, or $\overrightarrow{\vec{z}}$ both.

We would like to express our sincere gratitude to $\operatorname{Dr} 6$ Stig-Börje Mattson, who introduced us to the study of asbestos pleural effusion. These studies were supported by grants from the Swedish Work Environment Fund, the Swedish National $\vec{c}$ Association against Heart and Chest Diseases, and $\mathbb{D}$ the Swedish National Association for Heart and $\underset{\mathbb{D}}{\vec{D}}$ Lung Patients.

\section{References}

1 Eisenstadt HB. Asbestos pleurisy. Dis Chest 1964. 46:78-81.

2 Gaensler EA, Kaplan AI. Asbestos pleural effusion. Ann Intern Med 1971;74:178-91.

3 Sluis-Cremer GK, Webster I. Acute pleurisy in asbestos exposed persons. Environ Res 1972;5:380-92.

4 Chahinian PH, Hirsch A, Bignon J, et al. Les pleuresies asbestosiques non-tumorales. Rev Franc Mal Respir $\overrightarrow{\bar{\sigma}}$ 1973;1:5-39.

5 Lemenager J, Rousselot P, Mandard JG, et al. Les pleu- $\vec{\supset}$ resies beningnes de l'asbest. Rev Franc Mal Respir 1974;4 (suppl 2):75-86.

6 Boutin C, Viallat J, Farisse P, Choux R. Pleuresies asbestosiques benignes. Poumon Coeur 1975;3:111-8.

7 Mattson SB. Monoxymptomatic exudative pleurisy in persons exposed to asbestos dust. Scand J Respir Dis 1975;56:263-72.

8 Nyiredy G. Benigne asbestpleuritis. Prax Pneumol 1975;29:166-9.

9 Hillerdal G. Non-malignant asbestos pleural disease. Thorax 1981;36:669-75.

10 Robinson BWS, Musk AW. Benign asbestos pleuralơ effusion: diagnosis and course. Thorax 1981;36: 896-900.

11 Epler GR, McLoud TC, Gaensler EA. Prevalence and $N$ incidence of benign asbestos pleural effusion in a working population. JAMA 1982;247:617-22.

12 Becklake MR. State of the art-asbestos-related diseases $\widetilde{ }$ of the lung and other organs. Am Rev Respir Diso 1976;114:187-227.

13 Light RW. Pleural diseases. Philadelphia: Lea and Febiger, 1983:177-8.

14 Parkes WR. Occupational lung disorders. 2nd ed. London: Butterworths, 1982:293-4.

15 Mårtensson G, Pettersson K, Thiringer G. Differentiation between malignant and non-malignant 
pleural effusion. Eur J Respir Dis 1985;67:326-34.

16 Sarrazin W. Gesundheitliche Risiken durch Asbest: industrielle und allgemeine Expositionsmöglichkeiten. Prax Pneumol 1974;28:370-88.

17 Mackenzie FAF, Harries PG. Changing attitude to the diagnosis of asbestos disease. $J R$ Nav Med Serv 1970;56:116-23.

18 Hanke R, Kretzschmar R. Round atelectasis. Semin Roentgenol 1980;15:174-82.

19 Dernevik L, Gatzinksy P, Hultman E, Selin K, WilliamOlsson G, Zettergren L. Shrinking pleuritis with atelectasis. Thorax 1982;37:252-8.

20 Grimby G, Söderholm B. Static lung volumes and maximum voluntary ventilation in adults with a note on physical fitness. Acta Med Scand 1963;173:199-205.

21 Berglund E, Birath G, Bjure J, et al. Spirometric studies in normal subjects. Acta Med Scand 1963;173:185-92.

22 Sulavik S, Katz S. Pleural effusion. Springfield, Illinois: Charles C Thomas, 1963:53-5.

23 Light RW. Pleural diseases. Philadelphia: Lea and Febiger, 1983:122-3.

24 Gaensler EA. Idiopathic pleural effusion. $N$ Engl J Med 1970;283:816-7.

25 Lowell JR. Pleural effusions-a comprehensive review. Baltimore: University Park Press, 1977:88-93.
26 Mårtensson G, Hagmar B, Zettergren L. Diagnosis and prognosis in malignant pleural mesothelioma: a prospective study. Eur J Respir Dis 1984;65:169-178.

27 Mårtensson G, Bake B, Brolin I, Larsson S, Pettersson K, Thiringer G. Radiology and lung function after non-malignant pleural effusion. Eur $J$ Respir Dis (in press).

28 Lumley KPS. Physiological changes in asbestos pleural disease. In: Walton WH, McGovern B, eds. Inhaled particles IV. Oxford: Pergamon Press, 1977:781-88.

29 Wright PH, Hanson A, Kreel L, Capel LH. Respiratory function changes after asbestos pleurisy. Thorax 1980;35:31-6.

30 Turner-Warwick M, Parkes WR. Circulating rheumatoid and antinuclear factors in asbestos workers. $\mathrm{Br}$ Med J 1970;ii:492.

31 Kagan et al. Immunological studies in patients exposed to asbestos in the environment. $S$ Afr Med $J$ 1976;50:1009.

32 Lange A, Smolik R, Zatonski W, Szymanska J. Autoantibodies and serum immunoglobulin levels in asbestos workers. Int Arch Arbeitsmed 1974;32:313-25.

33 Kang KY, Sera Y, Okochi T, et al. T lymphocytes in asbestosis. N Engl J Med 1974;291:735-6. 